\title{
COPD-Tearch Paper COPD-Type lung inflammation promotes K-ras mutant lung cancer through epithelial HIF-1a mediated tumor angiogenesis and proliferation
}

\author{
Maria Miguelina De la Garza ${ }^{1,2}$, Amber M. Cumpian ${ }^{1}$, Soudabeh Daliri ${ }^{1}$, Susana \\ Castro-Pando ${ }^{1}$, Misha Umer ${ }^{1}$, Lei Gong ${ }^{1,3}$, Nasim Khosravi ${ }^{1}$, Mauricio S. Caetano ${ }^{1}$, \\ Marco Ramos-Castañeda ${ }^{1,2}$, Alejandra Garza Flores ${ }^{2}$, Evelyn C. Beltran², Hai T. \\ Tran $^{4}$, Michael J. Tuvim¹, Edwin J. Ostrin ${ }^{1,5}$, Burton F. Dickey ${ }^{1}$, Christopher M. \\ Evans $^{6}$ and Seyed Javad Moghaddam ${ }^{1,7}$

\footnotetext{
${ }^{1}$ Department of Pulmonary Medicine, The University of Texas M. D. Anderson Cancer Center, Houston, Texas, USA

${ }^{2}$ Tecnológico de Monterrey, Escuela de Medicina y Ciencias de la Salud, Monterrey, Nuevo León, Mexico

${ }^{3}$ Tianjin Lung Cancer Institute, Tianjin Medical University, Tianjin, China

${ }^{4}$ Department of Thoracic Head and Neck Medical Oncology, The University of Texas M. D. Anderson Cancer Center, Houston, Texas, USA

${ }^{5}$ Department of General Internal Medicine, The University of Texas M. D. Anderson Cancer Center, Houston, Texas, USA

${ }^{6}$ Division of Pulmonary Sciences and Critical Care Medicine, University of Colorado Denver School of Medicine, Aurora, Colorado, USA

${ }^{7}$ The University of Texas M.D. Anderson Cancer Center UTHealth Graduate School of Biomedical Sciences, Houston, Texas, USA
}

Correspondence to: Seyed Javad Moghaddam, email: smoghadd@mdanderson.org

Keywords: Iung cancer; COPD; HIF-1; inflammation; K-ras

Received: February 08, $2018 \quad$ Accepted: August 15, $2018 \quad$ Published: August 31, 2018

Copyright: De la Garza et al. This is an open-access article distributed under the terms of the Creative Commons Attribution License 3.0 (CC BY 3.0), which permits unrestricted use, distribution, and reproduction in any medium, provided the original author and source are credited.

\section{ABSTRACT}

Chronic obstructive pulmonary disease (COPD), an inflammatory disease of the lung, is an independent risk factor for lung cancer. Lung tissues obtained from human smokers with COPD and lung cancer demonstrate hypoxia and up-regulated hypoxia inducible factor-1 (HIF-1). HIF-1 activation is the central mechanism for controlling the cellular response to hypoxia during inflammation and tumor development. These facts suggest a link between COPD-related airway inflammation, HIF-1, and lung cancer. We have previously established a mouse model of COPD-like airway inflammation that promotes lung cancer in a K-ras mutant mouse model (CC-LR). Here we show that tumors in the CC-LR model have significantly elevated levels of HIF-1a and HIF-1 activity. To determine the tumor-promoting functions of HIF-1 in CC-LR mice, the gene Hif1a which encodes HIF-1a and is required for HIF-1 activity, was disrupted in the lung epithelium of CC-LR animals. Airway epithelial specific HIF-1a deficient mice demonstrated significant reductions in lung surface tumor numbers, tumor angiogenesis, and tumor cell proliferation in the absence or presence of COPDlike airway inflammation. In addition, when CC-LR mice were bred with transgenic animals that overexpress a constitutively active mutant form of human HIF-1a in the airway epithelium, both COPD- and adenocarcinoma-like phenotypes were observed. HIF-1a overexpressing CC-LR mice had significant emphysema, and they also showed potentiated tumorigenesis, angiogenesis, and cell proliferation accompanied by an invasive metastatic phenotype. Our gain and loss of function studies support a key role for HIF-1a in the promotion of lung cancer by COPD-like inflammation. 


\section{INTRODUCTION}

Cigarette smoking is the principal cause of chronic obstructive pulmonary disease (COPD) and lung cancer $[1,2]$. Although lung cancer is primarily caused by the induction of DNA mutations in lung epithelial cells, several studies have suggested that COPD-related risk for lung cancer is related to COPD-driven inflammation independently of cigarette smoke-induced mutagenesis [3-7]. Repeated cycles of respiratory tract epithelial mucosal damage and repair in response to chronic cigarette smoke exposure and/or infection in COPD can result in epithelial hyperplasia and metaplasia [8]. Although metaplasia is initially an adaptive response to persistent irritation, clinical surveillance has demonstrated that lung cancer often develops within metaplastic microenvironments [9]. Under non-neoplastic conditions, hyperplastic lesions can be induced transiently by inflammation or injury. However, when these lesions transit from having poorly controlled to uncontrolled proliferation, they take on neoplastic and atypical adenomatous appearances. The neoplastic transformation may be further accompanied by the acquisition of the growth, angiogenic, invasive, and metastatic characteristics of malignancy [10].

Due to the expansive activities within neoplastic structures, tumor cells are highly metabolic. However, they are poorly vascularized as they initially form, resulting in increased $\mathrm{O}_{2}$ demand amidst inadequate $\mathrm{O}_{2}$ supply. Accordingly, tumor cells experience significant hypoxia and they adapt to this environment by two means: up-regulation of anaerobic metabolic pathways (demand control) and up-regulation of pro-angiogenic pathways (supply control) [11-13]. Similarly, sites of inflammation (benign or neoplastic) are also characterized by local hypoxia and high glycolytic demands $[14,15]$. Under neoplastic and non-neoplastic conditions, hypoxic cells attempt to restore oxygen supply and demand homeostasis by activating compensatory response programs. A central mechanism for the cellular response to hypoxia occurs through regulation and activation of hypoxia inducible factor-1 (HIF-1) [16]. HIF-1 is a transcription factor that plays central roles in crucial aspects of carcinogenesis, including angiogenesis, cell survival, glucose metabolism, invasion, and metastasis. HIF-1 is a basic helix-loop-helix transcription factor [17] comprised of $\alpha$ and $\beta$ subunits. HIF-1 $\beta$ is constitutively produced but is inactive in the absence of HIF-1 $\alpha$, whose levels are directly controlled by oxygen levels, with normally high levels of oxygen causing proteolytic degradation of HIF-1 $\alpha$. Cellular hypoxia results in stabilization of HIF-1 $\alpha$, the formation of stabilized HIF- $1 \alpha / \mathrm{HIF}-1 \beta$ heterodimers, and the expression of HIF-target genes. In addition to increases in HIF-1 observed in lung cancer cells [18-20], hypoxia and up-regulated HIF-1 $\alpha$ have been shown in airway tissues obtained from human smokers with COPD [19], suggesting a potential role for inflammation-mediated hypoxia and HIF-1 pathway activation in the progression from COPD to lung cancer.

We have previously established a mouse model of COPD-like airway inflammation induced by repetitive exposure to an aerosolized lysate of non-typeable (i.e., unencapsulated) Hemophilus influenzae (NTHi), which commonly and persistently colonizes airways of COPD patients [21]. We have shown that this type of airway inflammation promotes lung cancer in a K-ras mutant mouse model [22]. NTHi-driven tumor promotion is associated with significant up-regulation of HIF- $1 \alpha$, and HIF-1 target genes [23], suggesting that HIF-1 activation during COPDlike inflammation that is independent of tobacco smoke may provide a crucial link between COPD and lung cancer.

To test whether COPD-like lung inflammation, and HIF-1 activation are linked causatively to lung cancer promotion, we studied the role of the HIF-1 $\alpha$ pathway using genetic targeting of this pathway in airway epithelial cells in mice in vivo. We found that COPDlike inflammation and HIF-1 $\alpha$ overexpression are each sufficient to potentiate K-ras induced lung tumorigenesis, and that HIF- $1 \alpha$ expression in the airway epithelium is required for tumor promotion, increased tumor angiogenesis, and cell proliferation.

\section{RESULTS}

\section{Lung cancer progression is associated with increased angiogenesis and activation of the HIF-1 $\alpha$ pathway}

We have previously found that NTHi-induced COPD-like airway inflammation upregulates HIF-1 $\alpha$ and vascular endothelial growth factor (VEGF) gene expression in the whole lung of a K-ras mutant mouse model of lung cancer (CC-LR or CCSP ${ }^{\mathrm{Cre}} / \mathrm{LSL}-\mathrm{Kras}^{\mathrm{G} 12 \mathrm{D}}$ mouse) [23]. These two genes (Hifla, and Vegf) have an important role in the regulation of angiogenesis, and we found significant angiogenesis in lung tumor tissues from CC-LR mice with NTHi-induced COPD-like inflammation (Figure 1A, 1B, and Supplementary Figure 1). This was associated with increased expression levels of HIF-1 $\alpha$ in nuclear extract of whole lung tissue lysates (Figure 1C), and VEGF in whole lung tissue lysates (Figure 1D) from CC-LR mice. These data further suggest a strong association between COPD-like lung inflammation, HIF$1 \alpha$ activity, angiogenesis and lung cancer promotion.

\section{Lack of HIF-1 $\alpha$ in the airway epithelium suppresses lung cancer promotion}

In order to study the causal role of HIF- $1 \alpha$ in lung cancer promotion, we have targeted its expression in the airway epithelium of the CC-LR mouse by crossing this mouse to a conditional knock out mouse with both alleles 
of exon 2 of Hifla flanked by loxP sites [24]. This resulted in a mouse that specifically expresses a mutant Kras allele while lacking HIF- $1 \alpha$ activity in the airway epithelium (LR/HIF-1 $\alpha^{\Delta / \Delta}$ ) because of the club cell secretory protein (CCSP) promoter which is directing Cre expression to airway secretory cells (club cells). This resulted in a $\sim 50 \%$ (1.8-fold) reduction in lung surface tumor number compared to age and sex-matched control CC-LR mice (44 \pm 6 in CC-LR vs $24 \pm 3$ in LR/HIF-1 $\alpha^{\Delta / \Delta}$ ) (Figure $2 \mathrm{~A}, 2 \mathrm{~B})$. HIF-1 $\alpha$ deficiency in the airway epithelium also significantly reduced the number of visible tumors on the lung surface of CC-LR mice by $>50 \%$ (2.2-fold) after inducing COPD-like airway inflammation using 8 weekly NTHi lysate exposures (162 \pm 5 in CC-LR NTHi treated vs $72 \pm 7$ in LR/HIF-1 $\alpha^{\Delta / \Delta}$ NTHi treated) (Figure 2A, 2B). Histopathologic examination of the lung from LR/HIF- $1 \alpha^{\Delta / \Delta}$ mice also showed less tissue inflammation and lower numbers of advanced adenomatous lesions compared to CC-LR mice (Figure 2A). Noticeably, HIF-1 $\alpha$ deficiency in the airway epithelium changed the bronchoalveolar lavage fluid (BALF) cellular component of CC-LR mice mostly by reducing the recruitment of macrophages into the lung at baseline and in response to NTHi exposure (Figure 2C). There were no significant changes in neutrophil or lymphocyte populations. Reduced macrophage number was associated with a significant reduction in levels of the pro-inflammatory cytokine IL-6 and chemokine KC (Table 1).

To study the mechanism of tumor reduction in mice with a lack of epithelial HIF-1 $\alpha$ activity, lung tissues were examined for angiogenesis, proliferation, and apoptosis using specific markers. CD31 as well as ERG staining of the lung from LR/HIF-1 $\alpha^{\Delta / \Delta}$ mice showed decreased microvessel density and reduced angiogenesis (Figure 3A, and Supplementary Figure 2A) along with reduced tumor cell proliferation (Figure 3B, and Supplementary Figure 2B) with no changes in tumor cell apoptosis (data not shown) compared to CC-LR mice in the presence or absence of NTHi-induced COPD-like airway inflammation.
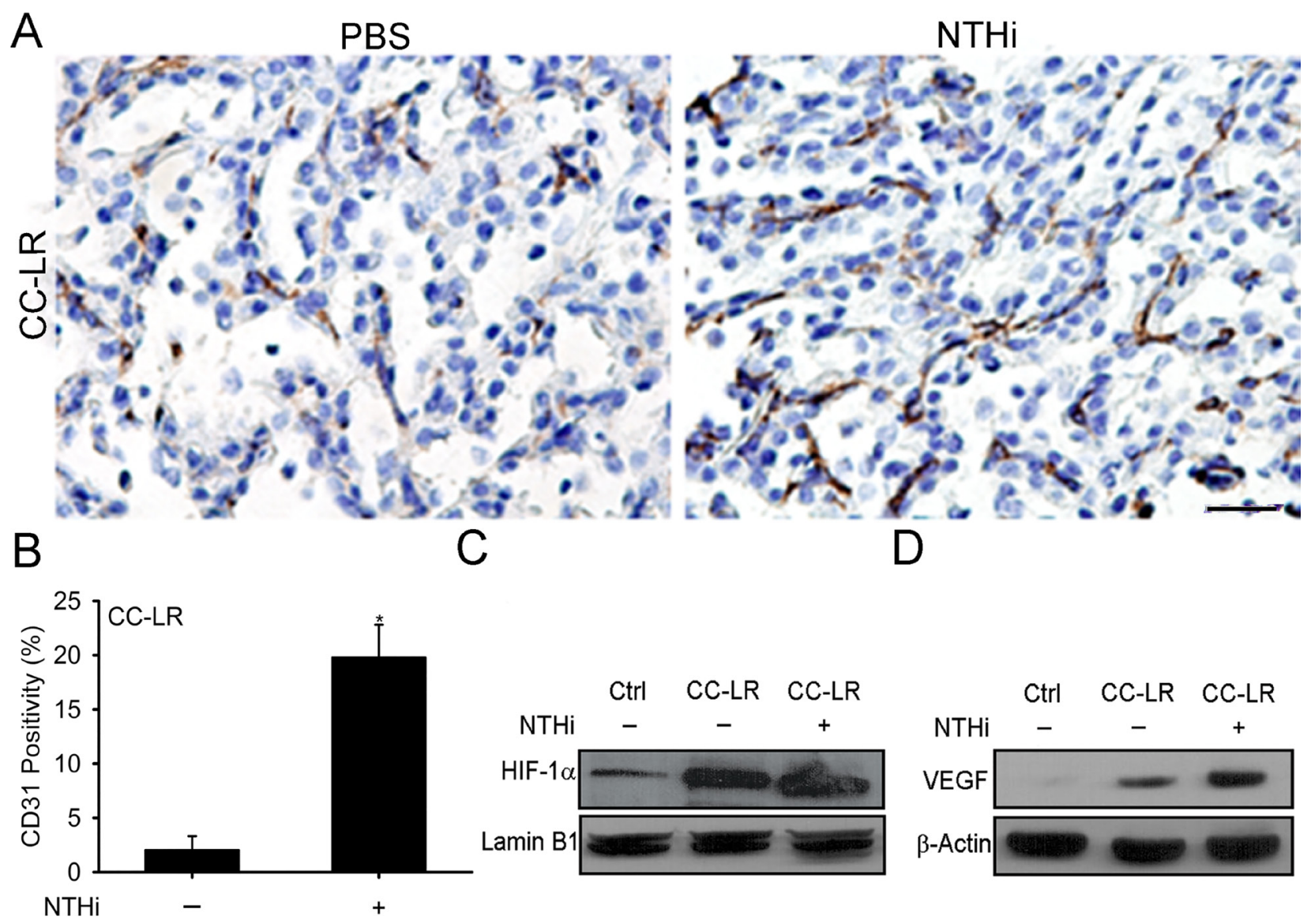

Figure 1: Promotion of K-ras induced lung tumorigenesis by inflammation is associated with increased angiogenesis and activation of the HIF-1 $\alpha$ pathway. (A) Representative photomicrographs of CD31 immunolabeled lung tumor tissues of 14 weeks old CC-LR mice in the absence or presence of NTHi-induced COPD-type airway inflammation (40× magnification, scale bar $=100 \mu \mathrm{m}$, applicable to all panels). (B) Quantitative analysis of CD31 positive staining in lung tissue of CC-LR mice in the absence or presence of NTHi exposure (mean $\pm \mathrm{SE} ;{ }^{*}=P \leq 0.05$ for CC-LR vs CC-LR plus NTHi; $n=3$ ). (C) Western blot analysis of HIF- $1 \alpha$ in the whole lung tissue nuclear extract. (D) Western blot analysis of VEGF in protein extracted from whole lung tissue. 


\section{Overexpression of HIF-1 $\alpha$ in the airway epithelium causes emphysema and promotes lung cancer}

To further confirm the promoting role of HIF$1 \alpha$ in lung cancer, we have developed a mouse with overexpression of HIF- $1 \alpha$ in the airway epithelium by crossing a CCSP-rtTA mouse to HIF- $1 \alpha$ Tg mouse (CCSP-rtTA/HIF-1 $\alpha$ Tg mouse) (Figure 4A, 4B).
Interestingly, this mouse $\left(\mathrm{rtTA}^{\mathrm{Tg}+} / \mathrm{HIF}-1 \alpha^{\mathrm{Tg}+}\right)$, when treated with doxycycline starting at the age of 6 weeks, developed an emphysematous lung phenotype with alveolar wall destruction and an abnormal enlargement of alveolar spaces compared to its transgene-negative control littermate ( $\mathrm{rtTA}^{\mathrm{Tg}+} / \mathrm{HIF}-1 \alpha^{\mathrm{Tg}}$ ) (Figure 4C, 4D, and Supplementary Figure 3), suggesting a role for HIF-1 $\alpha$ in COPD pathogenesis. The CCSP-rtTA/HIF- $1 \alpha$ Tg mouse was then crossed to the CC-LR mouse for development of

A

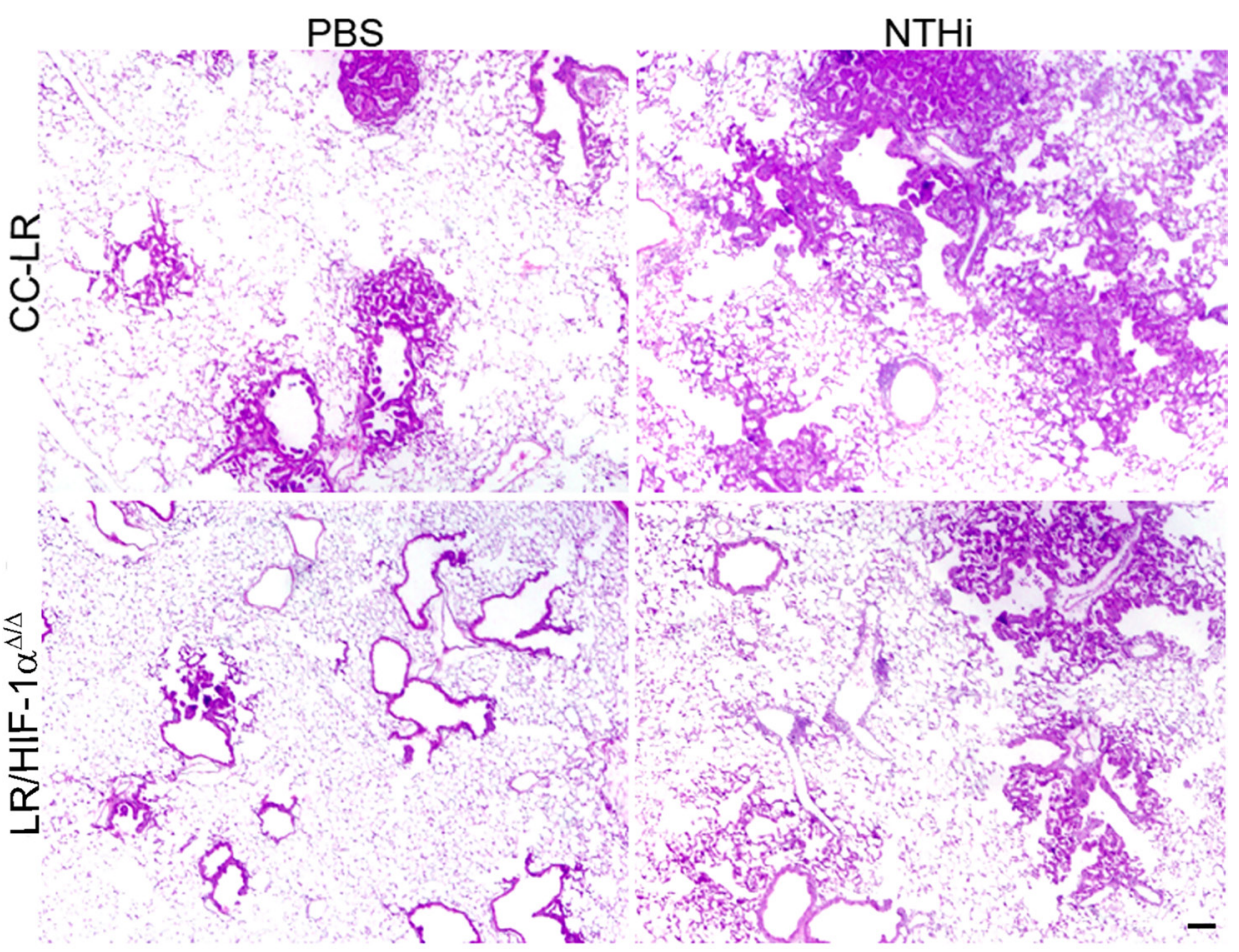

B

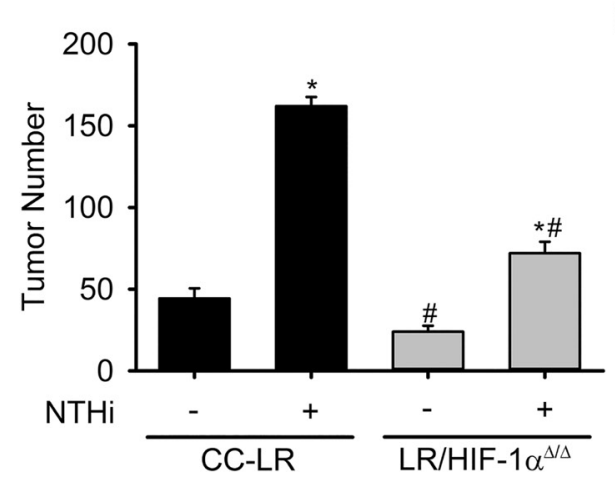

C

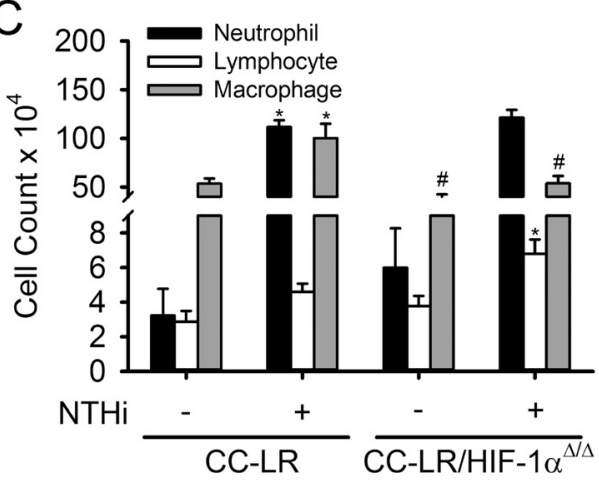

Figure 2: Lack of HIF-1 $\alpha$ in the airway epithelium suppresses K-ras induced lung tumorigenesis and its promotion by inflammation. CC-LR and LR/HIF-1 $\alpha^{\Delta \Delta}$ mice were exposed to an NTHi lysate aerosol starting at age 6 weeks weekly for 8 weeks to induce COPD-like airway inflammation. (A) Histopathological appearance of lung tissue from CC-LR and LR/HIF-1 $\alpha^{\Delta \Delta}$ in the absence or presence of COPD-type airway inflammation at age of 14 weeks ( $4 \times$ magnification, scale bar $=10 \mu \mathrm{m}$, applicable to all panels). (B) Lung surface tumor number in CC-LR and LR/HIF-1 $\alpha^{\Delta \Delta}$ mice in the absence or presence of COPD-type airway inflammation at age of 14 weeks (mean \pm SE; ",$P<0.05$ for CC-LR or LR/HIF-1 $\alpha^{\Delta \Delta}$ with NTHi exposure vs. without NTHi exposure; ${ }^{*}, P<0.05$ for CC-LR without NTHi exposure vs. LR/HIF-1 $\alpha^{\Delta / \Delta}$ without NTHi exposure or CC-LR with NTHi exposure vs. LR/HIF-1 $\alpha^{\Delta \Delta}$ with NTHi exposure; $n=12$ ). (C) Lineage-specific leukocyte numbers in BALFs of CC-LR and LR/HIF-1 $\alpha^{\Delta \Delta}$ mice 1 day after last NTHi aerosol exposure at age of 14 weeks (mean \pm SE; ${ }^{*}, P<0.05$ for CC-LR or LR/HIF-1 $\alpha^{\Delta \Delta}$ with NTHi exposure vs. without NTHi exposure; ${ }^{*}, P<0.05$ for CC-LR without NTHi exposure vs. LR/HIF-1 $\alpha^{\Delta / \Delta}$ without NTHi exposure or CC-LR with NTHi exposure vs. LR/HIF-1 $\alpha^{\Delta / \Delta}$ with NTHi exposure; $n=6$ ). 
Table 1: Selected cytokine and chemokine levels in bronchoalveolar lavage fluid

\begin{tabular}{|c|c|c|c|c|}
\hline \multirow{2}{*}{$\overbrace{\text { Mouse Group }}^{\text {Cytokine }}$} & \multicolumn{2}{|c|}{ IL-6 } & \multicolumn{2}{|c|}{$\mathrm{KC}$} \\
\hline & - NTHi & $+\mathbf{N T H i}^{*}$ & - NTHi & $+\mathbf{N T H i}^{*}$ \\
\hline CC-LR & $19.9 \pm 1.6$ & $131 \pm 3.0$ & $29.7 \pm 8.9$ & $126.7 \pm 9.4$ \\
\hline CC-LR/HIF-1 $\alpha^{\Delta / \Delta}$ & $2.09 \pm 0.6$ & $44.55 \pm 12.9$ & $16.98 \pm 7.5$ & $51.06 \pm 10.8$ \\
\hline CC-LR/HIF-1 $\alpha$ Tg & $61.61 \pm 9.2$ & N/A & $33.7 \pm 5.6$ & N/A \\
\hline
\end{tabular}

Abbreviations: NTHi, nontypeable Haemophilus influenza; IL-6, interleukin 6; KC, keratinocyte-derived chemokine, N/A, not applicable.

All data are the mean \pm SEM and are expressed as $\mathrm{pg} / \mathrm{ml}(n=4)$.

"Bronchoalveolar lavage fluids were collected at the age of 14 weeks and the first day after 8th NTHi exposure.

a mouse with mutant K-ras expression and overexpression of HIF- $1 \alpha$ in the airway epithelium (CC-LR/HIF- $1 \alpha$ Tg) when treated with doxycycline. A cohort of CC-LR/HIF-1 $\alpha$ $\mathrm{Tg}$ mice was treated with doxycycline chow from the age of 10 weeks for 4 weeks, then their lungs were studied for inflammation and tumors. Overexpression of HIF-1 $\alpha$ resulted in a significant increase $(\sim 50 \%, 1.8$-fold $)$ in lung surface tumor number in age and sex-matched CC-LR mice treated with the same amount and duration of doxycycline $(47 \pm 3$ in CC-LR $87 \pm 4$ in CC-LR/HIF-1 $\alpha \mathrm{Tg}$ ) (Figure 5A, 5B), which is less than the promoting effect of NTHi-induced COPD-type airway inflammation in the CC-LR model ( $\sim 3.2$-fold) as we have previously shown [22]. This was associated with a significant increase in levels of IL-6 and KC (Table 1), and subsequent recruitment of macrophages and neutrophils into the lung (Figure 5C).

Macroscopic and microscopic examination of the lungs from CC-LR/HIF-1 $\alpha \mathrm{Tg}$ mice showed slightly bigger tumors and the development of more papillarystructured advanced and invasive tumor phenotypes (Figure 5A) with metastatic invasion to the chest wall and intrathoracic lymph nodes (data not shown). No distant metastasis was found. Lung tumors from CC-LR/HIF-1 $\alpha$ $\mathrm{Tg}$ mice also showed increased expression of angiogenic (Figure 5D, and Supplementary Figure 4A) and proliferation (Figure 5E, and Supplementary Figure 4B) markers, but with no changes in apoptosis (data not shown).

\section{DISCUSSION}

A hypoxic tumor environment leads to necrosis of cells located far from vessels, but activation of HIF- $1 \alpha$ in surviving tumor cells closer to the vessels [25]. Later, this results in expression of genes in charge of neoangiogenesis (e.g. VEGFs and their receptors). Meanwhile, necrotic cells release intracellular molecules including alarmins and damage-associated molecular patterns, which trigger a proinflammatory response (intrinsic or tumor initiated inflammation) by activation of the NF- $\mathrm{KB}$ pathway that could further amplify the angiogenic signals initiated by HIF- $1 \alpha$ activity. On the other hand, just as hypoxia can induce inflammation, inflamed lesions in chronic inflammatory conditions (extrinsic inflammation) often become severely hypoxic as a result of increased metabolic demands or reduced metabolic substrates [26-29]. It is also known that HIF-1 expression is upregulated in response to inflammatory stimuli including IL-1 $\beta$, TNF, and bacterial products through pathways involving NF-kB, highlighting an interdependence of the innate immune and hypoxic responses to infection and tissue damage [28].

Here we have found that K-ras mutant lung tumorigenesis and its promotion by COPD-like airway inflammation is associated with significant tumor angiogenesis and activation of HIF- $1 \alpha$. Hypoxia and HIF- $1 \alpha$ activation also potentiate TLR4 expression, enhance the responses of macrophages to LPS, and result in the production of inflammatory cytokines, including IL-6 and TNF [30, 31]. We and others have previously demonstrated that these same signals, in the setting of COPD-type inflammation, promote lung tumorigenesis $[22,23,32,33]$. We have further shown that deleting HIF- $1 \alpha$ in the airway epithelium results in significant tumor reduction and reduced angiogenesis while its overexpression in the epithelium has the opposite effect, resulting in COPD-type inflammation, emphysema and tumor progression. This supports the epithelial HIF-1 $\alpha$ pathway activation as an essential process for the transition between COPD and lung cancer. HIF-1 $\alpha$ activation was associated with increases in the levels of the inflammatory cytokine IL-6 and chemokine $\mathrm{KC}$, which we have already shown to have essential roles in K-ras mutant lung tumorigenesis and its promotion by COPDtype airway inflammation [23,34]. Chronic inflammation in COPD could result in local hypoxia in inflamed or remodeled tissues (lungs) via decreased supply (i.e., reduced $\mathrm{O} 2$ diffusion through edematous tissue, airway, and thickened mucus or through vascular shunting and decreased $\mathrm{O} 2$ delivery to the epithelium), or it could occur via increased demand due to excessive $\mathrm{O} 2$ consumption by epithelial cells which ultimately leads to activation of the HIF-1 $\alpha$ pathway. 
In addition to inflammation and structural remodeling that occur in COPD, HIF-1 $\alpha$ expression has also been shown to be increased in basal and goblet cells in the lungs of smokers with COPD compared with healthy smokers, with expression localized almost exclusively to areas of airway remodeling [19, 35], and in positive association with expression of VEGF [36]. In addition, a conserved consensus motif for HIF-1 binding in the promotor of the Muc5ac mucin gene has been demonstrated [37], suggesting the possible involvement of hypoxia-inducible signaling in up-regulation of mucus production, a hallmark of lung adenocarcinoma. It has been shown that HIF-1 signaling promotes goblet cell metaplasia and hyperplasia in airway epithelium in an in vitro model using human bronchial epithelial cells [35]. Taken together, these data demonstrate a prominent role

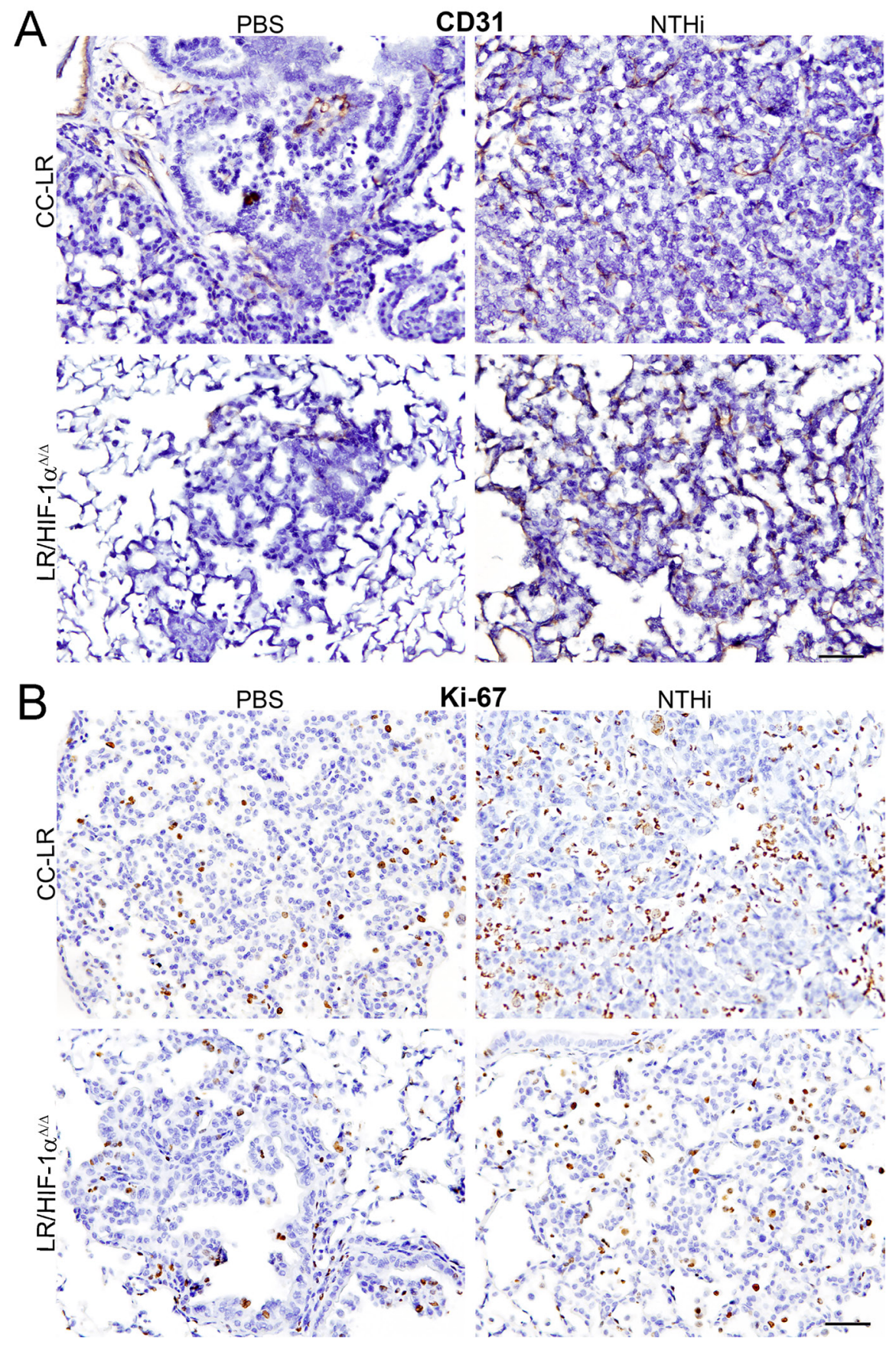

Figure 3: Lack of HIF-1 $\alpha$ in the airway epithelium suppresses tumor cell proliferation and angiogenesis. Representative photomicrographs of immunohistochemically stained lung tissue from CC-LR and LR/HIF-1 $\alpha^{\Delta / \Delta}$ mice in the absence or presence of NTHiinduced COPD-type airway inflammation at age of 14 weeks for angiogenesis marker, CD31 (A), or proliferation marker, Ki-67 (B) (20× magnification, scale bar $=50 \mu \mathrm{m}$, applicable to all panels). 
for HIF-1 mediated epithelial differentiation in COPD and perhaps its transition to lung cancer.

In human non-small cell lung cancer (NSCLC), overexpression of HIF-1 was found in $32.2 \%$ of primary resectable tumors and this was associated with reduced patient survival and increased tumor re-occurrence [18]. HIF-1 expression in epithelial cells is seen in all types of NSCLCs, including squamous and adenocarcinoma tumor types, as well as in small cell lung cancer $[19,20]$. It has been shown that treatment with a small molecule inhibitor of HIF-1 $\alpha$, PX-478, inhibited progression and spread of orthotopic human small cell lung cancer and lung adenocarcinoma in mice [38]. However, in contrast to our finding, in mice injected with A549 cells, silencing HIF-1 $\alpha$ impaired tumor vascularization and increased the necrotic area, but did not reduce tumor cell proliferation and only slightly impacted tumor growth [39]. Note that this study was done using a xenograft model in immunedeficient mice, which does not fully recapitulate the lung tumor microenvironment. On the other hand, it has been found that knockdown of HIF-1 $\alpha$ in a human NSCLC cell line results in the restoration of cytotoxic $\mathrm{T}$ lymphocytemediated tumor cell lysis under hypoxic conditions [40]. The divergent effects of HIF-1 $\alpha$ silencing in these studies suggest a complex regulation of tumor growth and invasion that is not controlled simply by the absence or presence of HIF-1, but rather may be dependent on different pathways interacting with the HIF pathway in tumor cells and the tumor microenvironment.

Taken together, we conclude that HIF-1 $\alpha$, an essential transcription factor that is activated in COPD and lung tumors, is essential for the lung tumor-

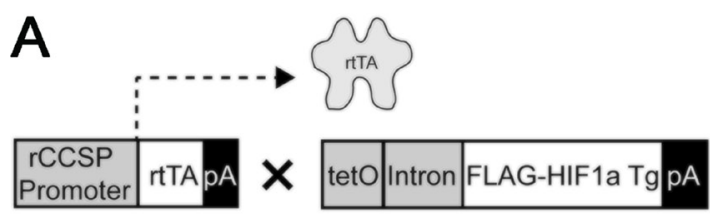

\section{B}
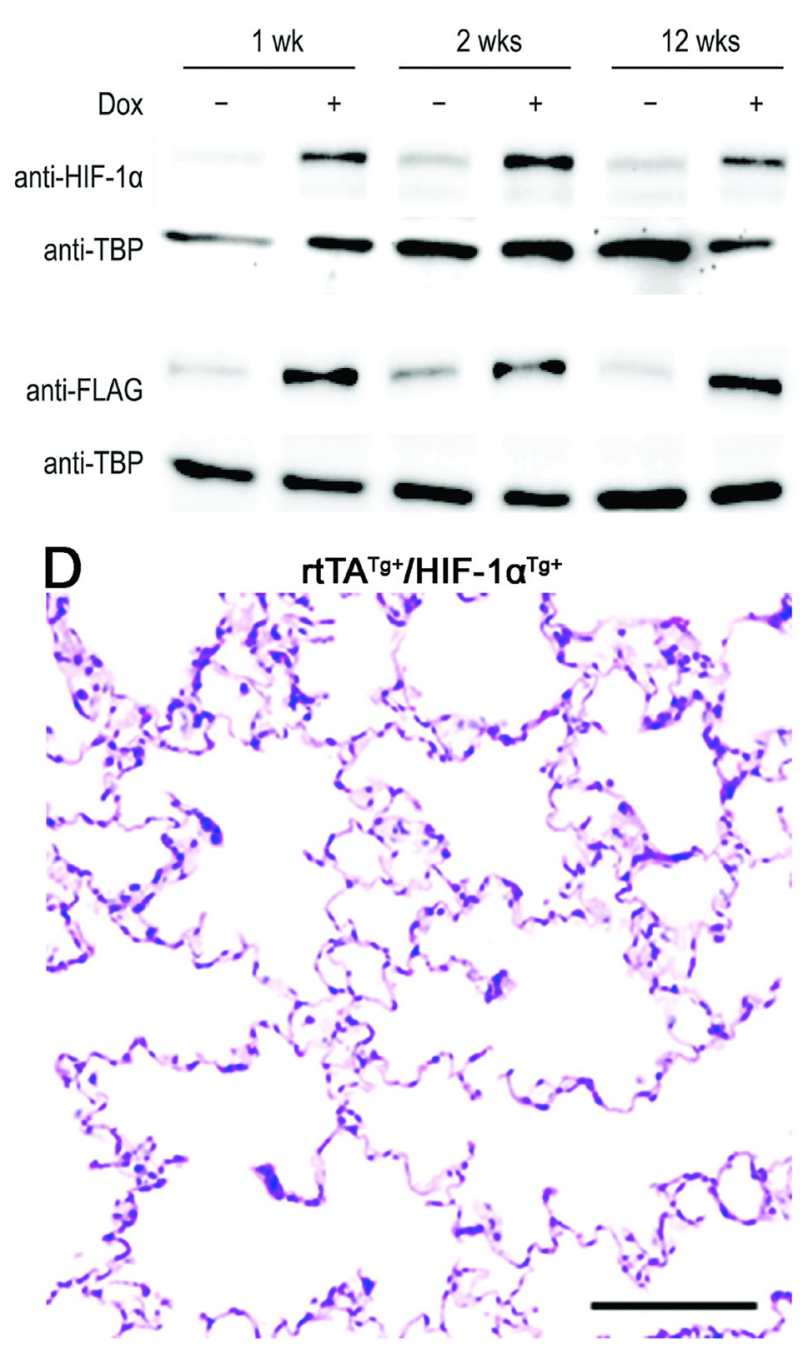

Figure 4: Structure and effect of the HIF-1 $\alpha$ transgene expression in the airway epithelium. (A) Schematic representation of HIF-1 $\alpha$ transgene construct and transgenic mouse development. (B) Immunoblotting to confirm endogenous and transgenic HIF-1 $\alpha$ protein production. (C, D) Representative photomicrographs of H\&E stained lungs from HIF-1 $\alpha$ transgene negative and positive mice showing airspace enlargement and alveolar wall destruction after doxycycline treatment in transgene positive but not negative mouse. 
promoting effect of COPD-associated inflammation, and can contribute to lung tumor progression and invasion by providing a microenvironment favoring tumor angiogenesis and tumor cell proliferation. Giving these facts, development of specific agents inhibiting this signaling pathway may represent a novel strategy for immunotherapeutic intervention, and might be beneficial for lung cancer prevention and treatment.

\section{MATERIALS AND METHODS}

Animals

CC-LR mice (CCSP $\left.{ }^{\mathrm{Cre}} / \mathrm{LSL}-\mathrm{Kras}^{\mathrm{G} 12 \mathrm{D}}\right)$ were generated as previously described [22]. Briefly, these are mice generated by crossing mice harboring a Lox-StopLox-Kras ${ }^{\mathrm{G} 12 \mathrm{D}}$ allele with mice containing Cre recombinase
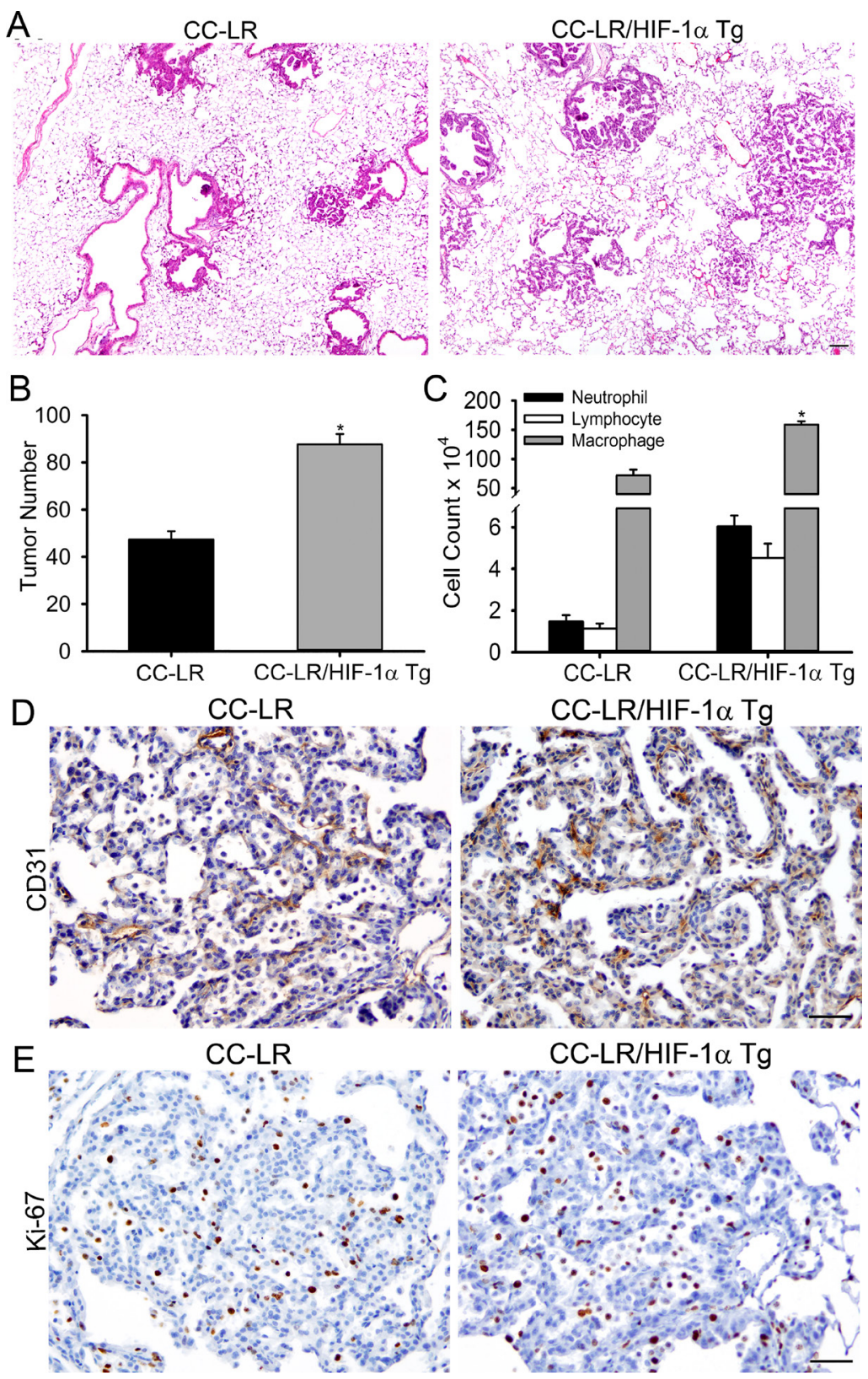

Figure 5: Overexpression of HIF-1a in the airway epithelium promotes K-ras induced lung tumorigenesis. (A) Histopathological appearance of lung tissue from CC-LR and CC-LR/HIF- $1 \alpha$ Tg at age of 14 weeks $(4 \times$ magnification, scale bar $=10 \mu \mathrm{m}$, applicable to all panels). (B) Lung surface tumor number in CC-LR and CC-LR/HIF-1 $\alpha$ Tg mice at age of 14 weeks (mean $\pm \mathrm{SE}$; ${ }^{*}, P$ $<0.05$ for CC-LR vs. CC-LR/HIF- $1 \alpha \mathrm{Tg} ; n=8)$. (C) Lineage-specific leukocyte numbers in BALFs of CC-LR and CC-LR/HIF-1 $\alpha$ Tg mice at age of 14 weeks (mean \pm SE; ${ }^{*}, P<0.05$ for CC-LR vs. CC-LR/HIF-1 $\alpha$ Tg; $n=4$ ). (D, E) Representative photomicrographs of immunohistochemically stained lung tissue from CC-LR and CC-LR/HIF-1 $\alpha$ Tg mice at age of 14 weeks for angiogenesis marker, CD31 (D), or proliferation marker, Ki67 (E) (20× magnification, scale bar $=50 \mu \mathrm{m}$, applicable to all panels). 
inserted into the CCSP locus; also called secretaglobin1a1, Scgb1a1; (we will use CCSP for the rest of this paper) [22]. K-ras mutant airway-specific HIF-1 $\alpha$ knock out $\left(\mathrm{LR} / \mathrm{HIF}-1 \alpha^{\Delta / \Delta}\right)$ mice were generated by crossing CC-LR mice to HIF-1 $\alpha^{\mathrm{F} / \mathrm{F}}$ mice previously generated by Dr. Randalll Johnson [24] and kindly provided by Dr. John Shannon of the Cincinnati Children's Hospital Medical Center. CCSP-rtTA Tg (line 2) mice and tetO-Cre mice were provided by Dr. Jeffrey A. Whitsett of the Cincinnati Children's Hospital Medical Center [41]. These mice were used to generate a transgenic mouse with overexpression of HIF-1 $\alpha$ in the airway epithelium as described below. All mice were housed in specific pathogen-free conditions and handled in accordance with the Institutional Animal Care and Use Committee of MD Anderson Cancer Center. Mice were monitored daily for evidence of disease or death.

\section{NTHi lysate aerosol exposure}

A lysate of NTHi strain 12 was prepared as previously described [21], the protein concentration was adjusted to $2.5 \mathrm{mg} / \mathrm{ml}$ in phosphate buffered saline (PBS), and the lysate was frozen in $10 \mathrm{ml}$ aliquots at $-80^{\circ} \mathrm{C}$. To deliver the lysate to mice by aerosol, a thawed aliquot was placed in an AeroMist CA209 nebulizer (CIS-US) driven by $10 \mathrm{l} / \mathrm{min}$ of room air supplemented with $5 \% \mathrm{CO} 2$ for $20 \mathrm{~min}$. CC-LR and CC-LR/HIF- $1 \alpha^{\Delta / \Delta}$ mice were exposed to the lysate starting at 6 weeks of age once a week for 8 weeks.

\section{Generation of conditional HIF-1 $\alpha$ transgenic mice}

HIF-1 $\alpha$ levels are controlled at both the transcript and protein levels. At the protein level, HIF-1 $\alpha$ is tightly regulated by an $\mathrm{O}_{2}$ sensitive degradative pathway that involves the activities of prolyl and asparaginyl hydroxylase proteins [17]. These utilize 2-oxoglutarate (2OG, also called $\alpha$-ketoglutarate) generated during aerobic metabolism as an oxygen donor for hydroxylation of HIF- $1 \alpha$. When $\mathrm{O}_{2} / 2 \mathrm{OG}$ levels are normal, HIF-1 $\alpha$ is down-regulated by functional and degradative means. A human HIF- $1 \alpha$ cDNA plasmid construct used previously for overexpression in cell lines [42] was re-engineered to generate doxycycline-inducible transgenic mice by mutating these hydroxylation targets (Figure 4A, 4B). The final construct used for cloning encoded an N-terminal FLAG-epitope tag, followed by a HIF-1 $\alpha$ cDNA mutated such that prolines 402 and 564 were substituted with alanine and glycine, respectively, and asparagine 803 was substituted with alanine. These mutations prevent degradation and promote transcriptional activation of HIF-1 $\alpha$ (a constitutively active transgene).

A tetO transgenic targeting construct was generated by modifying a transgenic vector we used previously to overexpress TNF in mouse lungs [21, 37]. In this case, the mouse CCSP promoter fragment was excised and a tetracycline operator-cytomegalovirus fusion promoter was inserted in its place. The FLAG-tagged constitutively active HIF- $1 \alpha$ cDNA described above was inserted into the tetO-expression cassette using cloned NheI sites, and orientation was confirmed by DNA sequencing. The final targeting construct (Figure 4A) was injected into C57BL/6 pro-nuclei at the MD Anderson Cancer Center Genetically Engineered Mouse Facility.

To induce transgene expression, tetO-HIF-1 $\alpha \mathrm{Tg}$ mice were crossed with rat CCSP-rtTA Tg (line 2) mice [41]. Resulting progeny were placed on a doxycycline supplemented diet (625 mg doxycycline/kg chow) at defined time points. The doxycycline diet was consumed ad libito and changed weekly. To confirm endogenous and transgenic HIF-1 $\alpha$ protein production, tissues were disrupted, and nuclear proteins were purified using a NEPER Nuclear and Cytoplasmic Extraction Reagents kit (Thermo Scientific, Rockford, IL, USA), and $25 \mu \mathrm{g}$ protein samples were separated on 7.5\% SDS-PAGE gels under reducing conditions. Proteins were transferred to PVDF membranes and analyzed by immunoblotting with antiHIF-1 $\alpha$ (1:500, Novus Biologicals, Littleton, CO, USA), anti-FLAG (Sigma, St. Louis, MO, USA), and anti-TATAbinding protein (1:5,000, Novus Biologicals) antibodies. Blots were probed with HRP-conjugated goat-anti-mouse IgG light chain specific secondary antibodies (1:10,000, $2 \mathrm{~h}$, Jackson ImmunoResearch, West Grove, PA, USA), then developed using chemiluminescent Super Signal West Femto HRP substrate detection (Thermo Scientific), and were imaged using a ChemiDoc XRS (Bio-Rad, Hercules, CA, USA). Duplicate gels and transfers were run, so antiHIF- $1 \alpha$ and anti-FLAG antibodies would not overlap (Figure 4B). Anti-TBP loading controls were performed for each blot. Transgenic progeny were subsequently crossed to CC-LR mice for development of CC-LR/HIF$1 \alpha$ Tg mice and placed on a Dox diet as described above. Generation and genotypes of all mouse models used in this study are summarized in Supplementary Table 1.

\section{Western blot analysis}

Total proteins were prepared from each group of mouse lungs as follows. Lung samples were removed and immediately placed in RIPA buffer and a protease inhibitor mixture. The samples were then homogenized and centrifuged at $14000 \mathrm{~g}$ for $20 \mathrm{~min}$ at $4^{\circ} \mathrm{C}$. The supernatants were collected as the total proteins. Nuclear proteins were extracted using NE-PER Nuclear Protein Extraction Kit (Pierce, IL, USA) according to the instructions. Protein concentrations were measured using the Bradford protein assay (Bio-Rad Laboratories). Equal amounts (50 $\mu \mathrm{g}$ for total proteins and $20 \mu \mathrm{g}$ for nuclear proteins) of the proteins were boiled for $5 \mathrm{~min}$ in loading buffer, loaded on each lane, and separated by $10 \%$ SDS-PAGE. The gels were then transferred to nitrocellulose membranes. Equal amounts of protein loading for each lane was checked by Ponceau (Sigma Chemical Co., MO, USA) staining. The anti-VEGF, 
anti-HIF- $1 \alpha$, anti-Lamin-B1 and anti- $\beta$-actin (Abcam, Cambridge, United Kingdom) antibodies were diluted to 1:1000. Immunoreactive bands were detected with Pierce ECL Western Blotting Substrate (Pierce, IL, USA).

\section{Histochemistry and immunohistochemistry}

Tissues were taken from mice with the following genotypes: CC-LR, LR/HIF-1 $\alpha^{\Delta / \Delta}$, CCSP-rtTA/HIF-1 $\alpha$ $\mathrm{Tg}$, and CC-LR/HIF-1 $\alpha$ Tg. Mice were anesthetized and sacrificed by intraperitoneal (IP) injection of avertin (Sigma, St. Louis, MO, USA), then the tracheas of euthanized mice were cannulated with PE50 tubing and sutured into place. The lungs were infused with $10 \%$ buffered formalin (Sigma), removed, and placed in $10 \%$ buffered formalin for $18 \mathrm{~h}$. Tissues then were transferred to $75 \%$ ethanol, embedded in paraffin blocks and sectioned at $5-\mu \mathrm{m}$ thickness. The sections on glass slides were dried at $60^{\circ} \mathrm{C}$ for $15 \mathrm{~min}$, and then were deparaffinized and stained with hematoxylin and eosin (H\&E) by incubating the tissues in Harris hematoxylin (Sigma) followed by serial eosin (Sigma) and graded ethanol steps. The H\&E stained slides were examined by a pathologist blinded to genotype and treatment, and the proliferative lesions of the lungs were evaluated in accordance with the recommendations of the Mouse Models of Human Cancer Consortium [43]. The severity of lung inflammation was also evaluated based on the extent of the lung tissue involvement with inflammatory lesions in H\&E stained slides. Alveolar space was measured using the D2 index from $20 \times$ magnification lung images from each mouse, ten images each, three mice per group as previously described [44]. Formalin-fixed, paraffinembedded sections $(5 \mu \mathrm{m})$ were also labeled with antiCD31 (1:10, BD Biosciences, CA, USA), anti-ETS-related gene (ERG) (1:1000, Abcam, MA, USA), anti-cleaved caspase 3 (CC3) (1:500, Abcam, MA, USA), and antiKi-67 (1:200, Abcam, MA, USA) antibodies after antigen retrieval. Slides were then incubated with biotinylated IgG secondary antibodies specific for each primary antibody followed by incubation with $\mathrm{ABC}$ kit (Vector Laboratory, Burlingame, CA, USA) for $30 \mathrm{~min}$, developed with diaminobenzidine (Vector, Burlingame, CA, USA) for 4-10 min, and counterstained with hematoxylin (Sigma-Aldrich). Images were obtained by an OLYMPUS BX 60 inverted microscope at $4 \times, 10 \times, 20 \times$ or $40 \times$ magnification with Image-Pro Plus, version 4.5.1.22. The numbers of labeled positive cells for CD31, ERG, and Ki-67 were quantitated as a fraction of total tumor nuclei per high power field $(40 \times)$ in 10 fields from three mice of each group. Results were expressed as a percentage of positive cells \pm standard error of the mean (SEM).

\section{Assessment of lung tumor burden and inflammation}

On the first day after the final NTHi exposure, animals were euthanized by IP injection of a lethal dose of avertin.
In all mice, lung surface tumor numbers were counted, then in some of them, the lungs were prepared for histological analysis as described above. In other mice, BALF was obtained by sequentially instilling and collecting two aliquots of $1 \mathrm{ml}$ PBS through a tracheostomy cannula. Total leukocyte count was determined using a hemacytometer, and cell populations were determined by cytocentrifugation of $300 \mu \mathrm{l}$ of BALF followed by WrightGiemsa staining. The remaining $\operatorname{BALF}(\sim 1,400 \mu \mathrm{l})$ was centrifuged at $1,250 \times g$ for $10 \mathrm{~min}$, and supernatants were collected and stored at $-70^{\circ} \mathrm{C}$. Cytokine concentrations in BALFs were measured in duplicate by multiplex bead-based assay (EMDMillipore, Bilerica, MA, USA) using a Luminex 200 analyzer (Luminex Corp, Austin, TX, USA) as detailed previously [45].

\section{Statistical methods}

Summary statistics for cell counts in BALF, and quantitative staining of CD31 in tumors were computed within treatment groups, and analysis of variance with adjustment for multiple comparisons was performed to examine the differences between the mean cell counts of the control group and each of the NTHi treatment groups. For tumor counts, comparisons of groups were made using Student's $t$-test. Differences were considered significant for $P<0.05$.

\section{Abbreviations}

COPD: chronic obstructive pulmonary disease; HIF-1: hypoxia inducible factor-1; CC- LR: CCSP ${ }^{\mathrm{Cre}} / \mathrm{LSL}-$ Kras $^{\mathrm{G} 12 \mathrm{D}}$; LSL: Lox-Stop-Lox; Scgb1a1: secretaglobin1a1; Dox: Doxycycline; HRP: horse radish peroxidase; IP: intra peritoneal; H\&E: hematoxylin and eosin; BALF: bronchoalveolar lavage fluid; NTHi: non-typeable Hemophilus influenzae; VEGF: vascular endothelial growth factor; CCSP: club cell secretory protein; NF$\kappa \mathrm{B}$ : nuclear factor-kappa B; LPS: Lipopolysaccharides; IL-6: interleukin 6; TNF: tumor necrosis factor; $\mathrm{KC}$ : keratinocyte-derived chemokine; Muc5ac: mucin 5AC; NSCLC: non-small cell lung cancer.

\section{Author contributions}

S.J.M. and M.M.D.G. designed research; M.M.D.G., S.D., S.C., A.M.C., M.U., L.G., N.K., M.S.C., M.R.C., A.G.F., E.C.B., H.T., M.J.T., C.M.E., and S.J.M. performed research; M.J.T., E.J.O., B.F.D., and C.M.E. contributed new reagents/analytic tools; M.M.D.G., M.R.C., C.M.E., and S.J.M. analyzed data; M.M.D.G., E.J.O., B.F.D., C.M.E., and S.J.M. wrote the paper; and S.J.M. supervised and conceptualized the study. 


\section{CONFLICTS OF INTEREST}

The authors declare no potential conflicts of interest.

\section{FUNDING}

This work was supported by a grant [RSG-11-11501-CNE] from American Cancer Society, and a StartUp fund from UT M. D. Anderson Cancer Center, both awarded to Seyed Javad Moghaddam.

\section{REFERENCES}

1. Postma DS, Bush A, van den Berge M. Risk factors and early origins of chronic obstructive pulmonary disease. Lancet. 2015; 385:899-909. https://doi.org/10.1016/ S0140-6736(14)60446-3.

2. Herbst RS, Heymach JV, Lippman SM. Lung cancer. N Engl J Med. 2008; 359:1367-80. https://doi.org/10.1056/ NEJMra0802714.

3. de-Torres JP, Wilson DO, Sanchez-Salcedo P, Weissfeld JL, Berto J, Campo A, Alcaide AB, Garcia-Granero M, Celli BR, Zulueta JJ. Lung cancer in patients with chronic obstructive pulmonary disease. Development and validation of the COPD Lung Cancer Screening Score. Am J Respir Crit Care Med. 2015; 191:285-91. https://doi.org/10.1164/ rccm.201407-12100C.

4. Takiguchi Y, Sekine I, Iwasawa S, Kurimoto R, Tatsumi K. Chronic obstructive pulmonary disease as a risk factor for lung cancer. World J Clin Oncol. 2014; 5:660-6. https://doi. org/10.5306/wjco.v5.i4.660.

5. de Torres JP, Bastarrika G, Wisnivesky JP, Alcaide AB, Campo A, Seijo LM, Pueyo JC, Villanueva A, Lozano MD, Montes U, Montuenga L, Zulueta JJ. Assessing the relationship between lung cancer risk and emphysema detected on low-dose CT of the chest. Chest. 2007; 132:1932-8.

6. Mannino DM, Aguayo SM, Petty TL, Redd SC. Low lung function and incident lung cancer in the United States: data From the First National Health and Nutrition Examination Survey follow-up. Arch Intern Med. 2003; 163:1475-80.

7. Shacter E, Weitzman SA. Chronic inflammation and cancer. Oncology (Williston Park). 2002; 16:217-26, 29.

8. Puchelle E, Zahm JM, Tournier JM, Coraux C. Airway epithelial repair, regeneration, and remodeling after injury in chronic obstructive pulmonary disease. Proc Am Thorac Soc. 2006; 3:726-33. https://doi.org/10.1513/ pats.200605-126SF.

9. Vine MF, Schoenbach VJ, Hulka BS, Koch GG, Samsa G. Atypical metaplasia and incidence of bronchogenic carcinoma. Am J Epidemiol. 1990; 131:781-93.

10. Hanahan D, Weinberg RA. Hallmarks of cancer: the next generation. Cell. 2011; 144:646-74. https://doi. org/10.1016/j.cell.2011.02.013.
11. Le QT, Chen E, Salim A, Cao H, Kong CS, Whyte R, Donington J, Cannon W, Wakelee H, Tibshirani R, Mitchell JD, Richardson D, O'Byrne KJ, et al. An evaluation of tumor oxygenation and gene expression in patients with early stage non-small cell lung cancers. Clin Cancer Res. 2006; 12:150714. https://doi.org/10.1158/1078-0432.CCR-05-2049.

12. Harris AL. Hypoxia-a key regulatory factor in tumour growth. Nat Rev Cancer. 2002; 2:38-47. https://doi. org/10.1038/nrc704.

13. Graves EE, Vilalta M, Cecic IK, Erler JT, Tran PT, Felsher D, Sayles L, Sweet-Cordero A, Le QT, Giaccia AJ. Hypoxia in models of lung cancer: implications for targeted therapeutics. Clin Cancer Res. 2010; 16:4843-52. https:// doi.org/10.1158/1078-0432.CCR-10-1206.

14. Saadi S, Wrenshall LE, Platt JL. Regional manifestations and control of the immune system. FASEB J. 2002; 16:849-56.

15. Zinkernagel AS, Johnson RS, Nizet V. Hypoxia inducible factor (HIF) function in innate immunity and infection. $\mathrm{J}$ Mol Med. 2007; 85:1339-46.

16. Semenza GL. Hypoxia-inducible factors: mediators of cancer progression and targets for cancer therapy. Trends Pharmacol Sci. 2012; 33:207-14. https://doi.org/10.1016/j. tips.2012.01.005.

17. Semenza GL. Targeting HIF-1 for cancer therapy. Nat Rev Cancer. 2003; 3:721-32.

18. Hung JJ, Yang MH, Hsu HS, Hsu WH, Liu JS, Wu KJ. Prognostic significance of hypoxia-inducible factor-1alpha, TWIST1 and Snail expression in resectable non-small cell lung cancer. Thorax. 2009; 64:1082-9. https://doi. org/10.1136/thx.2009.115691.

19. Polosukhin VV, Lawson WE, Milstone AP, Egunova SM, Kulipanov AG, Tchuvakin SG, Massion PP, Blackwell TS. Association of progressive structural changes in the bronchial epithelium with subepithelial fibrous remodeling: a potential role for hypoxia. Virchows Arch. 2007; 451:793-803.

20. Zhong H, De Marzo AM, Laughner E, Lim M, Hilton DA, Zagzag D, Buechler P, Isaacs WB, Semenza GL, Simons JW. Overexpression of hypoxia-inducible factor 1alpha in common human cancers and their metastases. Cancer Res. 1999; 59:5830-5.

21. Moghaddam SJ, Clement CG, De la Garza MM, Zou X, Travis EL, Young HW, Evans CM, Tuvim MJ, Dickey BF. Haemophilus influenzae lysate induces aspects of the chronic obstructive pulmonary disease phenotype. Am J Respir Cell Mol Biol. 2008; 38:629-38.

22. Moghaddam SJ, Li H, Cho SN, Dishop MK, Wistuba II, Ji L, Kurie JM, Dickey BF, DeMayo FJ. Promotion of lung carcinogenesis by chronic obstructive pulmonary diseaselike airway inflammation in a K-ras-induced mouse model. Am J Respir Cell Mol Biol. 2009; 40:443-53.

23. Ochoa CE, Mirabolfathinejad SG, Ruiz VA, Evans SE, Gagea M, Evans CM, Dickey BF, Moghaddam SJ. 
Interleukin 6, but not T helper 2 cytokines, promotes lung carcinogenesis. Cancer Prev Res (Phila). 2011; 4:51-64.

24. Ryan HE, Poloni M, McNulty W, Elson D, Gassmann M, Arbeit JM, Johnson RS. Hypoxia-inducible factor-1alpha is a positive factor in solid tumor growth. Cancer Res. 2000; 60:4010-5.

25. Tafani M, Pucci B, Russo A, Schito L, Pellegrini L, Perrone GA, Villanova L, Salvatori L, Ravenna L, Petrangeli E, Russo MA. Modulators of HIF1alpha and NFkB in Cancer Treatment: Is it a Rational Approach for Controlling Malignant Progression. Front Pharmacol. 2013; 4:13. https://doi.org/10.3389/fphar.2013.00013.

26. Eltzschig HK. Targeting Hypoxia-induced Inflammation. Anesthesiology. 2011; 114:239-42. https://doi.org/10.1097/ ALN.0b013e3182070c66.

27. Jung YJ, Isaacs JS, Lee S, Trepel J, Neckers L. IL-1betamediated up-regulation of HIF-1alpha via an NFkappaB/ COX-2 pathway identifies HIF-1 as a critical link between inflammation and oncogenesis. FASEB J. 2003; 17:2115-7.

28. Nizet V, Johnson RS. Interdependence of hypoxic and innate immune responses. Nat Rev Immunol. 2009; 9:609-17.

29. Rius J, Guma M, Schachtrup C, Akassoglou K, Zinkernagel AS, Nizet V, Johnson RS, Haddad GG, Karin M. NF-kappaB links innate immunity to the hypoxic response through transcriptional regulation of HIF-1alpha. Nature. 2008; 453:807-11.

30. Peyssonnaux C, Cejudo-Martin P, Doedens A, Zinkernagel AS, Johnson RS, Nizet V. Cutting edge: Essential role of hypoxia inducible factor-1alpha in development of lipopolysaccharideinduced sepsis. J Immunol. 2007; 178:7516-9.

31. Kim SY, Choi YJ, Joung SM, Lee BH, Jung YS, Lee JY. Hypoxic stress up-regulates the expression of Toll-like receptor 4 in macrophages via hypoxia-inducible factor. Immunology. 2010; 129:516-24.

32. Gong L, da Silva Caetano M, Cumpian AM, Daliri S, Garza Flores A, Chang SH, Ochoa CE, Evans CM, Yu Z, Moghaddam SJ. Tumor necrosis factor links chronic obstructive pulmonary disease and K-ras mutant lung cancer through induction of an immunosuppressive pro-tumor microenvironment. Oncoimmunology. 2016; 5:e1229724. https://doi.org/10.1080/2162402X.2016.1229724.

33. Moghaddam SJ, Barta P, Mirabolfathinejad SG, AmmarAouchiche Z, Garza NT, Vo TT, Newman RA, Aggarwal BB, Evans CM, Tuvim MJ, Lotan R, Dickey BF. Curcumin inhibits COPD-like airway inflammation and lung cancer progression in mice. Carcinogenesis. 2009; 30:1949-56.

34. Gong L, Cumpian AM, Caetano MS, Ochoa CE, De la Garza MM, Lapid DJ, Mirabolfathinejad SG, Dickey BF, Zhou Q, Moghaddam SJ. Promoting effect of neutrophils on lung tumorigenesis is mediated by CXCR2 and neutrophil elastase. Mol Cancer. 2013; 12: 154. https://doi. org/10.1186/1476-4598-12-154.

35. Polosukhin VV, Cates JM, Lawson WE, Milstone AP, Matafonov AG, Massion PP, Lee JW, Randell SH, Blackwell TS. Hypoxia-inducible factor-1 signalling promotes goblet cell hyperplasia in airway epithelium. J Pathol. 2011; 224:203-11. https://doi.org/10.1002/path.2863.

36. Lee SH, Lee SH, Kim CH, Yang KS, Lee EJ, Min KH, Hur GY, Lee SH, Lee SY, Kim JH, Shin C, Shim JJ, In KH, et al. Increased expression of vascular endothelial growth factor and hypoxia inducible factor-1alpha in lung tissue of patients with chronic bronchitis. Clin Biochem. 2014; 47:552-9. https://doi.org/10.1016/j.clinbiochem.2014.01.012.

37. Young HW, Williams OW, Chandra D, Bellinghausen LK, Perez G, Suarez A, Tuvim MJ, Roy MG, Alexander SN, Moghaddam SJ, Adachi R, Blackburn MR, Dickey BF, et al. Central Role of Muc5ac Expression in Mucous Metaplasia and Its Regulation by Conserved 5' Elements. Am J Respir Cell Mol Biol. 2007; 37:273-90.

38. Jacoby JJ, Erez B, Korshunova MV, Williams RR, Furutani K, Takahashi O, Kirkpatrick L, Lippman SM, Powis G, O'Reilly MS, Herbst RS. Treatment with HIF1alpha antagonist PX-478 inhibits progression and spread of orthotopic human small cell lung cancer and lung adenocarcinoma in mice. J Thorac Oncol. 2010; 5:940-9.

39. Franovic A, Holterman CE, Payette J, Lee S. Human cancers converge at the HIF-2alpha oncogenic axis. Proc Natl Acad Sci USA. 2009; 106:21306-11. https://doi. org/10.1073/pnas.0906432106.

40. Noman MZ, Buart S, Van Pelt J, Richon C, Hasmim M, Leleu N, Suchorska WM, Jalil A, Lecluse Y, El Hage F, Giuliani M, Pichon C, Azzarone B, et al. The cooperative induction of hypoxia-inducible factor-1 alpha and STAT3 during hypoxia induced an impairment of tumor susceptibility to CTL-mediated cell lysis. J Immunol. 2009; 182:3510-21. https://doi.org/10.4049/jimmunol.0800854.

41. Perl AK, Zhang L, Whitsett JA. Conditional expression of genes in the respiratory epithelium in transgenic mice: cautionary notes and toward building a better mouse trap. Am J Respir Cell Mol Biol. 2009; 40:1-3. https://doi. org/10.1165/rcmb.2008-0011ED.

42. Evans SE, Xu Y, Tuvim MJ, Dickey BF. Inducible innate resistance of lung epithelium to infection. Annu Rev Physiol. 2010; 72:413-35.

43. Nikitin AY, Alcaraz A, Anver MR, Bronson RT, Cardiff RD, Dixon D, Fraire AE, Gabrielson EW, Gunning WT, Haines DC, Kaufman MH, Linnoila RI, Maronpot RR, et al. Classification of proliferative pulmonary lesions of the mouse: recommendations of the mouse models of human cancers consortium. Cancer Res. 2004; 64:2307-16.

44. Jacob RE, Carson JP, Gideon KM, Amidan BG, Smith CL, Lee KM. Comparison of two quantitative methods of discerning airspace enlargement in smoke-exposed mice. PLoS One. 2009; 4:e6670. https://doi.org/10.1371/journal. pone. 0006670 .

45. Lieu CH, Tran H, Jiang ZQ, Mao M, Overman MJ, Lin E, Eng C, Morris J, Ellis L, Heymach JV, Kopetz S. The association of alternate VEGF ligands with resistance to anti-VEGF therapy in metastatic colorectal cancer. PLoS ONE. 2013; 8: e77117. https://doi.org/10.1371/journal.pone.0077117. 